\title{
Striated Nephrogram as an Incidental Finding in MRI Examination of Children
}

\section{Streifiges Nephrogramm als Zufallsbefund nach Kontrast- mittelgabe bei Kindern in der MRT}

Authors

Affiliation
S. Strocka, I. Sorge, L. Ritter, F. W. Hirsch

Department of Pediatric Radiology, University of Leipzig, Germany

\section{Key words \\ - abdomen \\ - MR-imaging \\ - contrast agents}

received $\quad 1.6 .2015$

accepted 23.8.2015

Bibliography

Dol http://dx.doi.org/

10.1055/s-0041-106539

Published online: 13.11.2015

Fortschr Röntgenstr 2016; 188:

69-72 @ Georg Thieme Verlag

KG Stuttgart · New York .

ISSN 1438-9029

\section{Correspondence}

\section{Dr. Steffen Strocka}

Department of Pediatric

Radiology, University of Leipzig

Liebigstr. 20a

04103 Leipzig

Germany

Tel.: ++ 49/3 41/9726933

Fax: ++49/3 41/971 7449

steffen.strocka@medizin.

uni-leipzig.de

\section{Abstract}

$\nabla$

Purpose: A highly striated contrast pattern of the kidneys occasionally appears in abdominal MRI examinations of children following the administration of gadolinium. As this phenomenon is well known but has not yet been explicitly described in literature, we investigated how frequently and in which clinical context this occurred.

Material and Methods: 855 abdominal MRI examinations with contrast media of 362 children between 2006 and 2014 were analysed retrospectively.

Results: A striated renal parenchyma was found in a total of nine children and eleven examinations ( $1.3 \%$ of examinations) and did only occur at a field strength of 3 Tesla. Of these children, seven had previously had tumors and chemotherapy. In two children there was no evidence of a previously serious condition with medications or a kidney disease. All of them had a normal renal function.

Conclusion: A noticeably striated nephrogram in the later phase of an MRI examination following administration of gadolinium may appear as an incidental finding in examinations at 3 Tesla without pathological relevance.

Key points:

- striated nephrograms may appear at a field strength of 3 Tesla.

- incidental finding without pathological relevance.

Citation Format:

- Strocka S, Sorge I, Ritter L et al. Striated nephrogram as an incidental finding in MRI examination of children. Fortschr Röntgenstr 2016; 188: 69-72

\section{Zusammenfassung \\ $\nabla$}

Ziel: Streifige Nephrogramme in der Spätphase nach Gadolinumgabe bei abdominellen MRT-Untersuchungen von Kindern sind ein bekanntes Phänomen, das in der bisherigen MRT-Literatur nicht beschrieben wird. Ziel dieser retrospektiven Arbeit war daher, wie oft und in welchem klinischen $\mathrm{Zu}$ sammenhang streifige Nephrogramme auftauchen. Material und Methoden: Retrospektive Auswertung von 855 abdominellen, kontrastmittelgestützten MRT-Untersuchungen von insgesamt 362 Kindern im Zeitraum 2006 bis 2014.

Ergebnisse: Streifige Nephrogramme wurden bei neun Kindern und in elf Untersuchungen (1,3\% aller Untersuchungen) gefunden und wurden ausschließlich bei einer Feldstärke von 3 Tesla beobachtet. Sieben dieser Kinder hatten eine maligne Tumorerkrankung mit begleitender Chemotherapie. Bei zwei dieser Kinder lag keine maligne Grunderkrankung oder medikamentöse Dauertherapie vor. Alle betroffenen Kinder hatten eine normale Nierenfunktion.

Schlussfolgerung: Streifige Nephrogramme in der Spätphase von MRT-Untersuchungen nach Gadoliniumgabe können als Zufallsbefund bei Untersuchungen mit einer Feldstärke von 3 Tesla beobachtet werden und haben keine pathologische Relevanz.

Kernaussagen:

- streifige Nephrogramme nach Gadoliniumgabe können bei einer Feldstärke von 3 Tesla beobachtet werden.

- Zufallsbefund ohne sichere pathologische Relevanz.

\section{Introduction}

$\nabla$

Contrast-enhanced abdominal MRI is routinely used in diagnosing pediatric patients with all types of abdominal diseases. It is 
used in particular in the diagnosis and follow-up of both tumors and non-malignant diseases.

The cortical region of the renal parenchyma generally exhibits homogenous contrast following the administration of gadolinium. In individual cases, however, we have incidentally observed an unusually striated image in late phase contrast-enhanced images. As this phenomenon has not yet been explicitly described in scientific MRI literature, this retrospective article examines how frequently and in which clinical context striated MRI nephrograms appear in pediatric cases.

\section{Material and methods}

$\nabla$

Altogether, 855 contrast-enhanced MRIs performed over 362 patients ( 180 females, 182 males, ages $0-18$ ) between July 2006 and May 204 were evaluated. Of the 362 patients, 136 were examined for suspected tumors or to evaluate the course of known tumors, accounting for a total of 565 of the 855 examinations. The examinations were performed on a 1.5- (Intera, Philips; Amsterdam, Netherlands) and a 3-Tesla machine (Siemens Trio, Siemens Healthcare, Erlangen, Germany) using the contrast medium Omnis$\operatorname{can}^{\circledast}$ (GE Healthcare, Chalfont St Giles, U.K.), Dotarem ${ }^{\circledast}$ (Guerbet, Villepinte, France), Gadovist ${ }^{\circledR}$ (Bayer Schering Pharma AG, Berlin, Germany) und Multihance ${ }^{\circledR}$ (Bracco Diagnostics, Milan, Italy), which were administered intravenously according to weight ( $0.2 \mathrm{ml}$ per $\mathrm{kg}$ of body weight) (or $0.1 \mathrm{ml}$ per $\mathrm{kg}$ of body weight in the case of Gadovist). Depending on the clinical objective, either dynamic or non-dynamic sequences were performed following the administration of contrast agent. If a striated nephrogram was yielded, the following information was documented in addition to the underlying disease: the current medical history, the glomerular filtration rate (based on plasma creatine using the Schwartz formula) as kidney function marker, the contrast medium used and the respective dose as well as the time between administering contrast medium and the appearance of the striated nephrogram. All examinations were evaluated by a radiologist (S.S.) with four years' experience in MRI. Positive reports were evaluated by a second radiologist (F.W.H.) with 20 years' experience. If there was a discrepancy between the radiologists' evaluations, final assessment was reached through consensus.

\section{Results}

$\nabla$

A striated nephrogram was found in a total of 9 patients ( $\bullet$ Table 1 ), 5 males and 4 females, and in 11 examinations (3 positives for 1 patient), corresponding to a frequency of $1.3 \%$ ( Fig. 1, 2). The patients were children with different underlying diseases: 7 children were undergoing tumor assessment following chemotherapy (5 neuroblastomas as well as 1 contralateral nephroblastoma), accounting for $1.1 \%$ of all abdominal MRI examinations following administration of contrast medium. At the time of examination, two of these patients were in the midst of ongoing chemotherapy. For the remaining patients, the time span between their last chemotherapy and the MRI ranged between 7 months and 4 years. In addition, two of the children exhibiting remarkable nephrograms had no prior tumors and had not received chemotherapy or any other type of long-term therapy. One child had a venous malformation, while the other had a hepatic cyst. This accounted for $0.2 \%$ of all abdominal MRI examinations following administration of contrast medium.

At the time of examination, none of our patients exhibited impaired kidney function in terms of estimated glomerular filtration rate or infectious kidney disease.

The span of time between the administration of contrast medium and the appearance of the striated nephrogram ranged between 9 and 38 minutes with a median of 17.5 minutes. The contrast medium Dotarem ${ }^{\circledR}$ (Guerbet, Villepinte, France), was administered for 7 patients, Omniscan ${ }^{\circledR}$ (GE Healthcare, Chalfont St Giles, UK) for 1 patient and Gadovist $^{\circledR}$ (Bayer Schering Pharma AG, Berlin, Germany) for 1 patient as well, with Dotarem being used for a total of 512, Multihance for 30, Omniscan for 98 and Gadovist for 215 examinations. All striated nephrograms were observed exclusively with examinations performed on the 3-Tesla machine (Siemens Trio, Siemens Healthcare, Erlangen, Germany), which was used for 578 of the 855 examinations.

\section{Discussion}

Changes in the renal parenchyma, which normally exhibits homogenous contrast, have been described following the administration of contrast medium in CT examinations for various kidney diseases [1]. This unilateral or bilateral striated nephrogram seen on CT has been attributed to ob-

\begin{tabular}{|c|c|c|c|c|c|}
\hline pat. no. & $\begin{array}{l}\text { age } \\
\text { [in years] }\end{array}$ & underlying disease & $\begin{array}{l}\text { kidney function and } \\
\text { urine status }\end{array}$ & $\begin{array}{l}\text { time following administration of } \\
\text { contrast medium [in minutes] }\end{array}$ & $\begin{array}{l}\text { contrast medium } \\
\text { and dosage [in } \mathrm{ml}]\end{array}$ \\
\hline 1 & 5 & neuroblastoma stage I & n.p. & 10 & Dotarem; 4 \\
\hline 2 & 2 & neuroblastoma stage IV & n.p. & 16 & Dotarem; 3 \\
\hline 3 & 7 & neuroblastoma stage I & n.p. & 29 & Dotarem; 4 \\
\hline 4 & 1 & hepatic cyst & n.p. & 13 & Dotarem; 2 \\
\hline 5 & 4 & nephroblastoma & n.p. & $38,9,13$ & Dotarem; 6 \\
\hline 6 & 8 & neuroblastoma stage IV & n.p. & 11 & Omniscan; 15 \\
\hline 7 & 6 & neuroblastoma stage IV & n.p. & 23 & Dotarem; 4 \\
\hline 8 & 4 & venous malformation & n.p. & 15 & Dotarem; 4 \\
\hline 9 & 2 & hepatoblastoma & n.p. & 16 & Gadovist; 2 \\
\hline
\end{tabular}

Pat. no. $=$ patient number, $\min =$ minutes, $\mathrm{ml}=$ milliliter, $\mathrm{n} . \mathrm{p} .=$ not pathological. 


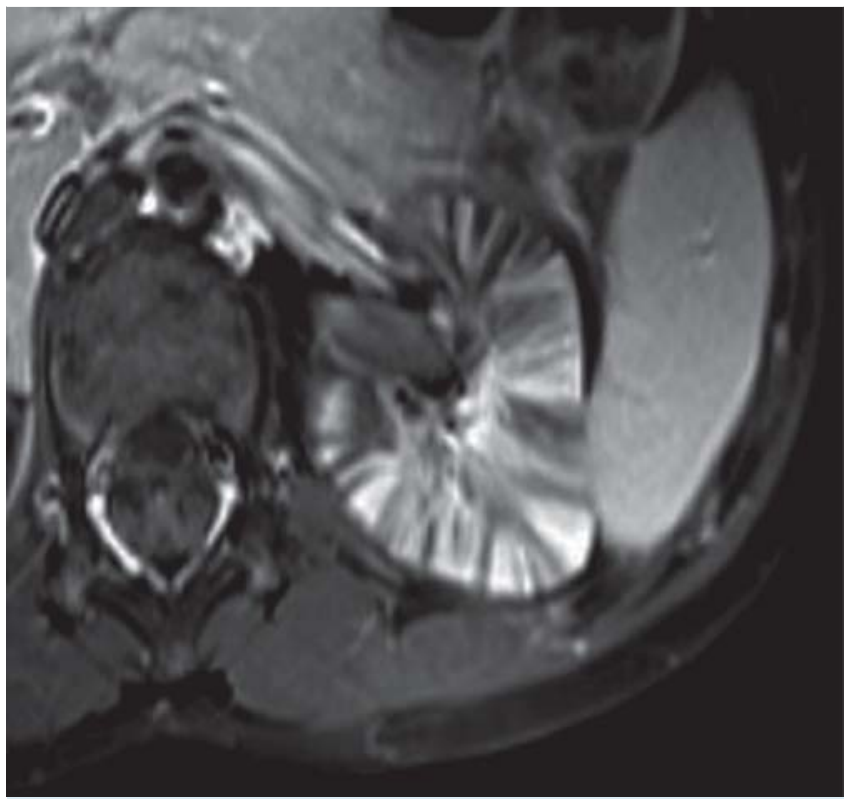

Fig. 1 Sample image of a striated nephrogram in a fat-saturated T1 spin echo sequence following administration of contrast medium in axial view.

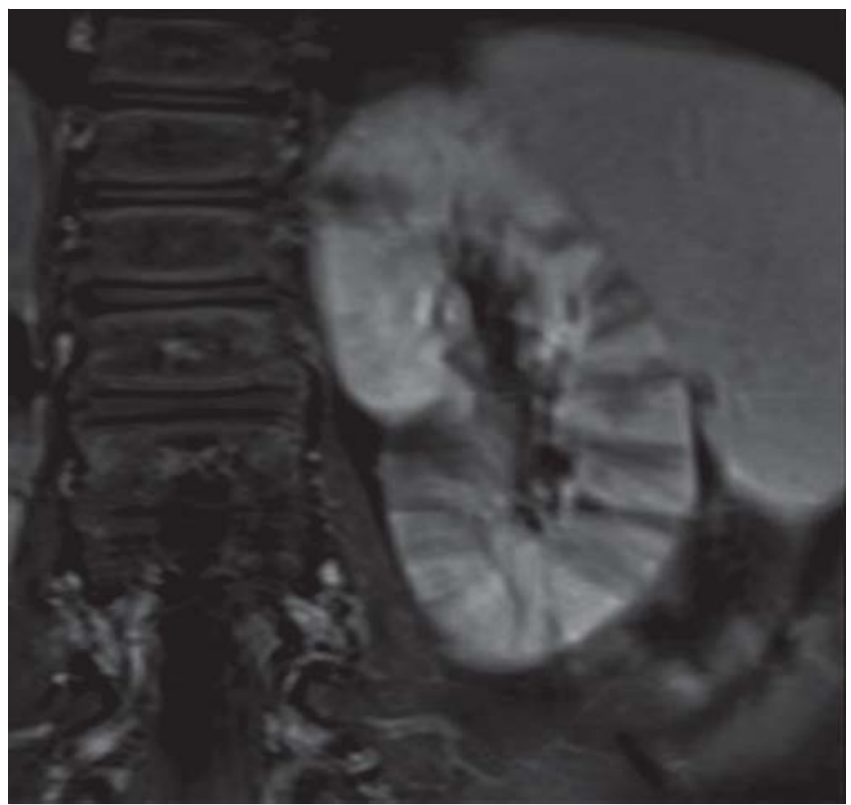

Fig. 2 Sample image of a striated nephrogram in a fat-saturated T1 spin echo sequence following administration of contrast medium in coronal view.

structive uropathy as well as renal vein thrombosis, trauma, arterial hypotension and acute cases of pyelonephritis [1]. In terms of their etiology, these changes in nephrogram involving remarkable striation following the administration of contrast medium were associated with a displacement of the renal tubules, e.g. resulting from the precipitation of proteins, with this finding initially being described in 1971 among patients with multiple myeloma [2]. However, other substrates such as, for example, TammHorsfall-proteins, uric acid, myoglobin in the case of rhabdomyolysis or dehydration have also been accepted as causal [1,3-6], a displacement of the tubules with consecutive stasis of the contrast medium having been discussed on the etiopathological level as a cause of the appearance of a striated nephrogram.

Although these striated signal decreases in MR nephrograms are likewise familiar to several radiologists, this phenomenon has not yet been addressed in scientific radiological literature on magnetic resonance imaging.

Because it was remarkable that there was a relatively long span of time between contrast medium being applied and the striated nephrogram appearing, the author's posit that the striated, signal-free zones in the renal parenchyma are possibly an accumulation of contrast medium and a contrast inversion resulting from an intensified T2 shortening effect when a very high gadolinium concentration is present, with the striated appearance being explained by the tubular structure of the tubules as they run from the renal cortex to the renal papilla.

This phenomenon observed more frequently in patients following chemotherapy may be caused by a stasis of the contrast medium in the tubules following prior chemotherapy, e.g. through damage thereto or through intraluminal deposits. However, because the same phenomenon was also visible in two cases in which we were unable to see a causal connection to a prior or acute disease, the striated nephrogram may also constitute an incidental, non-pathological finding in these cases. Supporting a non-pathological finding are also the facts that the striated nephrograms yielded for the patients in question were not replicated in the subsequent follow-up examinations and that the phenomenon appeared only in examinations performed on the 3-Tesla machine, implying a dependency on field strength. Arguing against this are the results of Trout et al. [7], who examined the same phenomenon and demonstrated an association between the appearance of a striated nephrogram and a specific MR scanner regardless of field strength. However, this study likewise concedes an absent causal pathology.

One limitation of the present study is that it is a retrospective assessment, thus meaning that the follow-up observation period was not of comparable length for all patients. If comparably long follow-up observation periods were employed, it would have to be assumed that the incidence of this incidental finding could increase. Another limitation was that different MR contrast media and non-uniform examination protocols were used.

\section{Conclusion}

Unlike in CT examinations, where it has been described only in connection with an underlying pathology, a remarkable striated nephrogram in the late phase of an MRI examination following the administration of contrast medium appears to occur as an incidental finding following the intravenous administration of contrast medium and presumably involves an intensified T2 shortening effect resulting from a high concentration of contrast media in the renal tubules, which is demonstrated particularly at a field strength of 3 Tesla, with presumably no pathological significance being attached to this finding. 


\section{References}

1 Dawson $P$ et al. Contrast-medium-induced acute renal failure and Tamm-Horsfall proteinuria. Br J Radiol 1984; 57: 577 - 579

2 Myers GH Jr, Witten DM. Acute renal failure after excretory urography in multiple myeloma. Am J Roentgenol Radium Ther Nucl Med 1971; 113: $583-558$

3 Hunnam GR, Sherwood T. Striated nephrogram in rhabdomyolysis. Br J Radiol 1985; 58: $682-683$

4 Martin DJ, Jaffe N. Prolonged nephrogram due to hyperurecemia. Br J Radiol 1971; 44: 806-809
5 Porter GA. Contrast associated nephropathy: presentation, pathophysiology and management. Miner Electolyte Metab 1994; 20: 232-243 6 Stunell $\mathrm{H}$ et al. Imaging of acute pyelonephritis in the adult. Eur Radiol 2007; 17: $1820-1828$

7 Trout A, Towbin A, Zhang B et al. The "Striated MR Nephrogram": An Infrequent Finding on Delayed Post-contrast Images of the Kidneys. Radiological Society of North America 2013 Scientific Assembly and Annual Meeting, December 1 - December 6, 2013, Chicago IL http:// archive.rsna.org/2013/13044395.html 